\title{
Childhood leukaemia in areas with different radon levels: a spatial and temporal analysis using GIS
}

\author{
S Kohli, H Noorlind Brage, O Löfman
}

\begin{abstract}
Objectives-To evaluate the relation between exposure to ground radon levels and leukaemia among children using existing population and disease registers. Design-Ecological correlation study. Setting-The county of Östergötland in Sweden.

Methods-Every child born in the county between 1979 and 1992 was mapped to the property centroid coordinates by linking addresses in the population and property registers. Population maps were overlaid with radon maps and exposure at birth and each subsequent year was quantified as high, normal, low or unknown. This was analysed with data from the tumour registry. Standardised mortality ratios (SMRs) were calculated using the age and sex specific rates for Sweden for the year 1995 .

Results-90 malignancies occurred among 53146 children (498 887 person years) who formed the study population. SMRs for acute lymphatic leukaemia (ALL) among children born in high, normal and low risk areas were $1.43,1.17$ and 0.25 respectively. The relative risk for the normal risk group and high risk group as compared with the low risk group was $4.64(95 \%$ CI $1.29,28.26)$ and 5.67 (95\% CI $1.06,42.27)$. The association between ALL and continued residence at normal or high risk areas showed a similar trend. No association between radon risk levels and any other malignancy was seen.

Conclusion-Children born in and staying at areas where the risk from ground radon has been classified as low are less likely to develop ALL than those born in areas classified as normal and high risk.

(F Epidemiol Community Health 2000;54:822-826)
\end{abstract}

Radon is one of the important sources of background radiation to which humans are exposed. The association of radon with lung cancers and other malignancies has been studied extensively. ${ }^{1-16}$ The association between radon and childhood malignancies was reported in several studies from Great Britain, ${ }^{5-7}$ and generated considerable debate. ${ }^{8-12}$ One study from the USA found an association between groundwater radon concentration and overall cancer mortality in children under 15 years with the strongest association for leukaemias. ${ }^{13}$ On the other hand a large case control study ${ }^{14}$ and at least two ecological analyses ${ }^{15} 16$ published recently failed to show any increased risk between residential radon exposure and childhood acute lymphatic leukaemia (ALL).
No large scale studies of risk from background radiation attributable to radon in children have been carried out in Sweden. Furthermore, in the context of an environmental risk factor, it is not enough to know just the spatial distribution of population at risk. The temporal aspect of the problem - that is, when did the exposure occur and for how long-is of equal, if not greater, importance. Against this background this study was undertaken to analyse both the spatial and temporal profile, using and adapting existing and available databases and health registers.

The specific objectives of this study were to:

(a) Extract from the existing population databases a subset of all children born in the county of Östergötland between 19791992.

(b) To link this database of children to the radon risk map of the county and to determine the level of risk they were exposed to at birth, and during the period of study.

(c) To determine the relation between exposure to high background radon and malignancies if any.

\section{Methods}

MAPS

The province of Östergötland in Sweden was the study area. Digital maps of the province were purchased from the "Lantmäteriverket", the Swedish Land Surveyor authority. The Swedish geological survey office has defined a national radon risk classification (table 1), by which all 13 communes in Östergötland, the entire area in seven of them and the densely populated areas or the areas planned for development in the remaining six, have been measured. The classification in high, possibly high, normal or low risk areas has been depicted on detailed paper maps, which were digitised by us in the Swedish national grid coordinate system.

STUDY POPULATION

The entire population of the county of Östergötland from the years 1979 to 1995

Table 1 Swedish geological survey office radon risk classification, including also factors like radon daughters and type, moisture and porosity of the soil. The classification is primarily meant to help local authorities in regulating land development and building codes and standards

\begin{tabular}{ll}
\hline Classification & $\begin{array}{l}\text { Concentration of radon (or daughters) } \\
\text { in Bequerel per cubic metre }\end{array}$ \\
\hline $\begin{array}{l}\text { High risk } \\
\text { Possibly high risk }\end{array}$ & $\begin{array}{l}50000 \\
\text { Insufficient measurements to } \\
\text { definitely classify as high risk but } \\
\text { likely to be high (borderline) }\end{array}$ \\
$\begin{array}{l}\text { Normal risk } \\
\text { Low risk }\end{array}$ & 10000 to 50000 \\
\hline
\end{tabular}


Property Register

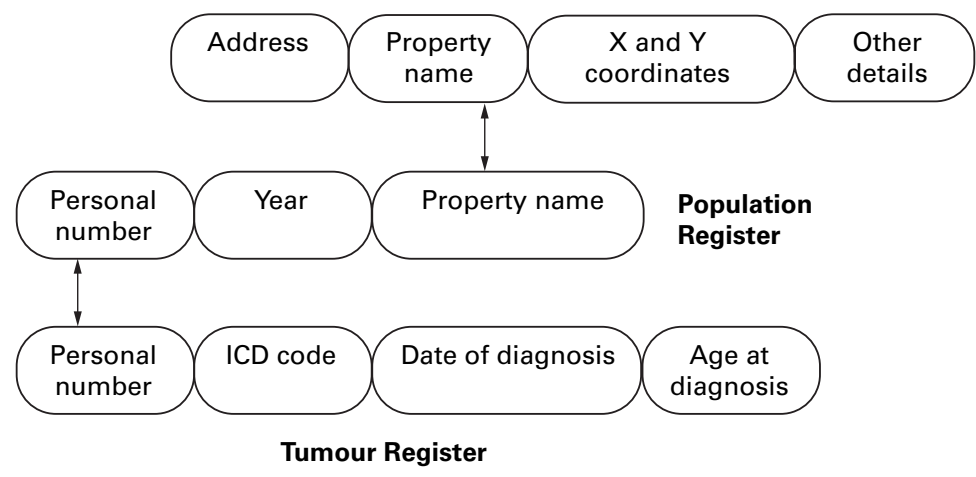

Figure 1 Diagrammatic representation of the linking of different registers.

formed the main database. Each resident in Sweden has a unique 10 digit personal number. The population register contains the personal number and the address of the person. It is obligatory for every person to notify any change of address. The population register, as on 31 December of each year, for the years 1979 to 1995 was obtained from the Swedish Central Statistical Bureau. The addresses in this population register were linked to the property register that contained the property coordinates. Each person was linked to the centroid of the property on which they resided. Details of this linking method have been described earlier ${ }^{17}{ }^{18}$ and depicted diagramatically in figure 1 . Thus a population database containing the personal number, age, sex and property centroid coordinates of each person, at birth and every continued year of residence in the county was generated.

A total of 68506 children were born during the period 1979-1992 in the county of Östergötland and formed the study population. The study period was from 1979 to 1995 , giving a follow up time for each child of at least three years. A map of the property was overlaid with digital radon maps using the MAPINFO package to add a field for risk classification to each property address. This was then linked back to the children's database resulting in a record for each child showing the personal number, the address at birth and for each year thereafter till 1995 and the risk stratification at each place of residence.

At this point 15360 children, 7914 boys and 7446 girls, who had, through the entire study period, resided in an area where the risk from radon was not measured, were excluded, leaving 53146 subjects in the study group. This table was then submitted to the regional cancer registry where another field was added to each record containing the ICD code of the type of cancer, if any, and the date of diagnosis. Data on 5902 children who had migrated out of Östergötland during the study period were submitted to the national cancer registry. The tumour registry used ICD-7 codes in the database sent back to us. However, for reasons of privacy protection the addresses, coordinates and personal numbers were removed from the records before the table was returned to us. The ultimate table contained the information as depicted in figure 2 .

The population was stratified by age group, sex and radon exposure classification. Risk stratification was considered in two different ways. The first was to assume the risk classification at birth to be effective for the entire study duration. The second strategy was to stratify individuals according to the risk levels they were exposed to during each year of residence during the study period. Continued exposure risk "high" meant that the person had only resided at high risk areas while "mixed" indicated that the person had shifted residence and the risk classification at each place of residence was different. Person years that each subject contributed to each age class was calculated according to the method described by Breslow and Day. ${ }^{19}$ As the number of subjects in the category "possibly high" was so small it was combined with the category "high".

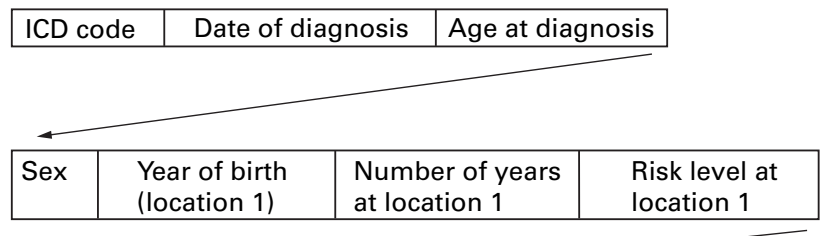

\begin{tabular}{|c|c|c|c|}
\hline $\begin{array}{l}\text { Year of entry } \\
\text { in location } 2\end{array}$ & $\begin{array}{l}\text { Age at entry into } \\
\text { location } 2\end{array}$ & $\begin{array}{l}\text { Number of years } \\
\text { at location } 2\end{array}$ & $\begin{array}{l}\text { Risk level at } \\
\text { location } 2\end{array}$ \\
\hline $\begin{array}{l}\text { Year of entry } \\
\text { in location } 17\end{array}$ & $\begin{array}{l}\text { Age at entry into } \\
\text { location } 17\end{array}$ & $\begin{array}{l}\text { Number of years } \\
\text { at location } 17\end{array}$ & $\begin{array}{l}\text { Risk level at } \\
\text { location } 17\end{array}$ \\
\hline
\end{tabular}

\begin{tabular}{|l|l|l|l|l|l|}
\hline $\begin{array}{l}\text { Number of } \\
\text { changes }\end{array}$ & $\begin{array}{l}\text { Total } \\
\text { years of } \\
\text { observation }\end{array}$ & $\begin{array}{l}\text { Total } \\
\text { years in high } \\
\text { risk area }\end{array}$ & $\begin{array}{l}\text { Total years in } \\
\text { low risk area }\end{array}$ & $\begin{array}{l}\text { Total years in } \\
\text { normal risk area }\end{array}$ & $\begin{array}{l}\text { Total years in } \\
\text { unknown risk } \\
\text { area }\end{array}$ \\
\hline
\end{tabular}

Figure 2 Table structure after the data were coupled with the tumour register. 
Table 2 Acute lymphatic leukaemia and exposure risk stratification at the place of birth

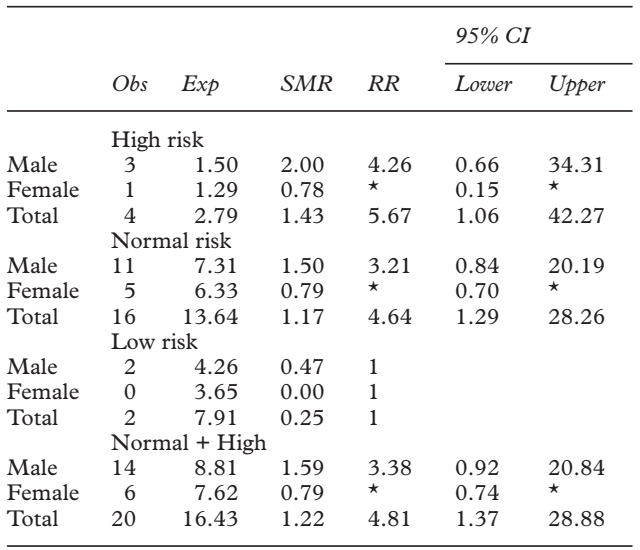

O: observed, E: expected, RR: interval estimation of relative risk, RR: $95 \%$ CI: $95 \%$ confidence limits of RR. ${ }^{\star}$ Values were not calculated as no cases occurred among women in the low risk group.

Standardised mortality ratios (SMRs) were calculated using the Swedish national age and sex specific rates for the follow up end year 1995 to calculate the expected values. Comparison of the groups was done according to the method described by Breslow and Day. ${ }^{20}$ Relative risk (RR) was calculated using the group classified as low exposure as the standard.

\section{Results}

A total of 90 malignancies were recorded among these 53146 children (498 887 person years) during the study period, 59 among boys and 31 among girls. There was no significant relation between the total number of malignancies and the continued exposure risk throughout the study period or with the risk level at the place of birth (not shown).

The incidence of ALL among children according to age, sex and risk stratification is shown in tables 2 and 3. It was noteworthy that only two cases of ALL occurred among children who were born in a low risk area and both were boys. However, before they developed ALL both of them had moved out of Östergötland where one had stayed only one
KEY POINTS

- There is evidence that children born in and continuously living in areas classified as high and normal risk for background radiation from radon have higher incidence of acute lymphatic leukaemia.

- There is a stronger association with continued residence at a higher risk area than with the risk at the place of birth.

- There is no evidence of a similar association of radon with other malignancies.

- In view of the increased incidence of acute lymphatic leukaemia even at the so called normal risk areas there is a need to reassess the classification of risk from background radon and enforcement of radon safe building standards.

year at a low risk area and five years at a normal risk area while the other had stayed at a low risk area for three years. There was a rising trend in the RR from low risk to high risk through normal, though this was significant only when findings for both sexes were combined. This relation was seen both with the risk at place of birth and the continued exposure risk through out the study period. SMRs for girls were markedly lower than for boys. The RR for girls separately was not calculated as no cases were recorded among girls in the low classification group.

\section{Discussion}

The main finding from our study is that children who were born in and continued to live in, areas classified as low risk attributable to radiation from ground radon had a lower RR for developing ALL as compared with children born in areas classified as normal or high risk. The association was significant for the total group but not for boys or girls individually. The association with continuous residence was even stronger. The visible trend between low risk, normal risk and high risk (RR 1:6.40:10.07) is interesting, suggesting a dose response relation similar to that indicated by Collman et al. ${ }^{13}$

Table 3 Acute lymphatic leukaemia and exposure risk stratification throughout the study period

\begin{tabular}{|c|c|c|c|c|c|c|c|c|c|c|c|c|c|c|c|c|c|c|}
\hline & \multicolumn{3}{|l|}{$0-4$ Years } & \multicolumn{3}{|c|}{ 5-9 Years } & \multicolumn{3}{|c|}{ 10-14 Years } & \multicolumn{3}{|c|}{ 15-16 Years } & \multicolumn{2}{|l|}{ Total } & \multirow[b]{2}{*}{$S M R$} & \multirow[b]{2}{*}{$R R$} & \multicolumn{2}{|c|}{$95 \% C I$} \\
\hline & $\begin{array}{l}\text { Person } \\
\text { years }\end{array}$ & $O$ & $E$ & $\begin{array}{l}\text { Person } \\
\text { years }\end{array}$ & $O$ & $E$ & $\begin{array}{l}\text { Person } \\
\text { years }\end{array}$ & $O$ & $E$ & $\begin{array}{l}\text { Person } \\
\text { years }\end{array}$ & $O$ & $E$ & $\mathrm{Obs}$ & $\operatorname{Exp}$ & & & Lower & Upper \\
\hline \multicolumn{19}{|c|}{ Always high risk } \\
\hline Male & 9060 & 1 & 0.62 & 5364 & 1 & 0.22 & 2135 & 1 & 0.07 & 230 & 0 & 0.00 & 3 & 0.91 & 3.30 & 7.65 & 0.84 & 197.54 \\
\hline Female & e 8252 & 1 & 0.63 & 4993 & 0 & 0.13 & 2304 & 0 & 0.04 & 294 & 0 & 0.01 & 1 & 0.81 & 1.23 & $\star$ & 0.13 & $\star$ \\
\hline Total & 17312 & 2 & 1.25 & 10357 & 1 & 0.35 & 4439 & 1 & 0.11 & 524 & 0 & 0.01 & 4 & 1.72 & 2.33 & 10.07 & 1.31 & 244.14 \\
\hline \multicolumn{19}{|c|}{ Always normal risk } \\
\hline Female & e 48900 & 5 & 3.72 & 29921 & 0 & 0.76 & 13207 & 0 & 0.22 & 1464 & 0 & 0.03 & 5 & 4.73 & 1.06 & $\star$ & 0.52 & $\star$ \\
\hline Total & 101758 & 12 & 7.36 & 62120 & 2 & 2.08 & 27307 & 1 & 0.66 & 3065 & 0 & 0.05 & 15 & 10.15 & 1.48 & 6.40 & 1.19 & 132.86 \\
\hline \multicolumn{19}{|c|}{ Always low risk } \\
\hline Male & 23012 & 0 & 1.59 & 13246 & 1 & 0.54 & 5644 & 0 & 0.18 & 613 & 0 & 0.01 & 1 & 2.32 & 0.43 & 1 & & \\
\hline Female & e 21152 & 0 & 1.61 & 12220 & 0 & 0.31 & 4964 & 0 & 0.08 & 556 & 0 & 0.01 & 0 & 2.01 & 0.00 & 1 & & \\
\hline Total & 44164 & 0 & 3.20 & 25466 & 1 & 0.85 & 10608 & 0 & 0.26 & 1169 & 0 & 0.02 & 1 & 4.33 & 0.23 & 1 & & \\
\hline \multicolumn{19}{|c|}{ Normal + High risk } \\
\hline Male & 61918 & 8 & 4.27 & 37563 & 3 & 1.54 & 16235 & 2 & 0.51 & 1831 & 0 & 0.02 & 13 & 6.34 & 2.05 & 4.76 & 0.87 & 99.69 \\
\hline Female & e 57152 & 6 & 4.34 & 34914 & 0 & 0.88 & 15511 & 0 & 0.25 & 1758 & 0 & 0.04 & 6 & 5.51 & 1.09 & $\star$ & 0.56 & $\star$ \\
\hline Total & 119070 & 14 & 8.61 & 72477 & 3 & 2.42 & 31746 & 2 & 0.76 & 3589 & 0 & 0.06 & 19 & 11.85 & 1.60 & 6.94 & 1.33 & 142.25 \\
\hline
\end{tabular}

O: observed, E: expected, RR: interval estimation of relative risk, RR: 95\% CI: 95\% confidence limits of RR. *Values were not calculated as no cases occurred among women in the low risk group. 
Even though interval $\mathrm{p}$ values are borderline, the lower $95 \%$ confidence levels for the normal and high risk group are above unity.

\section{STRENGTH AND WEAKNESSES OF THE STUDY} DESIGN

Malignancies and leukaemias are a heterogeneous group of diseases and may have a variety of causative factors. That apart, we have attempted to minimise selection bias by starting off with the entire population of children born in the county within the study period excluding only those continuously residing in areas with unknown risk from background radon. The groups were similar in their age and sex composition. In distinction from studies based on interviews with subjects or their parents for the quantification of the exposure, our study was based on more objective criteria of documented and recorded measurements of background radiation attributable to radon, thus avoiding recall bias.

The Swedish population registers are accurate and were available as the recorded address of a person as on 31 December of each year under study. It was assumed that the person had lived at the same address throughout the year. While it is theoretically possible that a person could have shifted twice in a year and to locations with different risk levels, the probability of that happening is presumably low enough to be ignored. It may also be argued that ground radon concentrations may differ from those found within the buildings. However, this would, if anything, lend strength to our findings as building in areas with high ground radon concentrations may have lower concentrations inside rather than vice versa.

Ecological correlational studies are also prone to other biases. ${ }^{21}{ }^{22}$ The most important is the ecological fallacy, which is reduced here as the study is not based upon aggregated but thorough individual information. As compared with mortality data in most studies we used total disease incidence, which is definitely superior. We also used geographical information (GIS) systems methods to accurately locate each person within the risk areas thus avoiding the pitfall of generalising the exposure values to administrative or postcode boundaries.

Significant results may arise by chance alone if a large number of tests of significance are made with respect to a number of cancer sites. We have tried to minimise this by making comparisons and analyses only for those total malignancies and ALL and by using a conservative method of statistical analysis. In the case of ALL, even though both the cases in the "non-exposed" group occurred after the individuals had moved out of Östergötland, we have taken them into account thus underestimating rather than over estimating the strength of the association.

RADON AND LEUKAEMIA

Association of myeloid leukaemia and radon was reported in the past by Lucie $^{5}$ and Henshaw $^{6}$ and has generated considerable debate. ${ }^{8-12}$ Other workers from the UK revealed correlations for several conditions, the strongest being for ALL. ${ }^{73}$ However, Thorne et al found no such associations ${ }^{16}$ but used indoor radon concentrations that may vary considerably over time and were assessed in a subset of $13 \%$ of the total dwellings averaged over the postcode districts. A recent case-control study likewise found no relation between ALL and indoor radon levels, ${ }^{14}$ which, however, were measured after the event. On the other hand, an increased risk of leukaemia with a more temporally stable surrogate for ground radon exposure, namely granite, has been reported from France $^{24}$ and support our findings. Furthermore, among children living in areas with high groundwater radon levels, Collman reported increased overall cancer and leukaemia mortality, ${ }^{13}$ and Gilman and Knox that it increased with increasing radon exposure in 12 complete annual cohorts independent of socioeconomic factors. ${ }^{25}$

RESIDENTIAL MOBILITY, PLACE OF BIRTH AND EXPOSURE EARLY IN LIFE

A study from the UK analysed the relation between migration patterns and leukaemia and, like our data, revealed no significant relation between the two. ${ }^{26}$ Knox and Gilman reported stronger hazard proximities for birth addresses than for death addresses among children dying from leukaemia and cancer. ${ }^{27}$ This brings up the question of an environmental insult either prenatally or in early childhood, which may make the children more "susceptible" to the development of ALL, and seems to be plausible when one considers that low dose ionising radiation from radiographic examination during pregnancy leads to definite increase in the incidence of childhood cancer. ${ }^{29-31}$ Gardner suggested that preconceptual paternal radiation may be a risk factor of childhood leukaemia. ${ }^{32}$ This hypothesis does seem tempting and may explain the association with the place of birth but has been negated by other reports. $^{33-35}$

One important public health question that arises from our study concerns building standards and ground radon levels. As has been pointed out earlier, the classification of areas into low, normal or high risk is the Swedish norm primarily for regulating building and construction standards. Buildings on high risk areas must compulsorily be made radon safe while these measures are recommended but are not compulsory on normal risk areas. The significantly increased risk of leukaemia in children born at normal risk areas suggests that these standards and classifications should be reviewed and radon safe measures be enforced even for buildings on normal risk areas.

CONCLUSION

There is evidence in our study that the incidence of ALL in children is related to the risk of radiation from background radon. There is a stronger association between the incidence of leukaemia and continued residence at high risk areas than with the risk level at the place of birth. Our study does not show any association of other malignancies with 
radon levels. We would like to emphasise that this is a preliminary correlational study and factors other than radon could be at play. There is, nevertheless, a definite need for further detailed analysis of the relation between radon and childhood leukaemias. We also suggest that the building standards for construction on the areas currently classified as normal risk be reviewed.

The authors gratefully acknowledge the assistance, advice and support of Professor Erik Trell of the Department of General
Practice and Professor Ove Wigertz of the Department of Practice and Professor Ove Wigertz of the Department of
Medical Informatics at the University of Linköping. Thanks are also due to Örjan Foldemo who helped in matching the tumour register with our database and to Anders Magnusson for helping us understand statistics.

Funding: the study was partly supported by a research grant from the County Council of Östergötland, Sweden.

Conflicts of interest: none.

1 Axelson O. Cancer risks from exposure to radon in homes. Environ Health Perspect 1995;103 (suppl 2):37-43.

2 Lubin JH, Boice Jr JD. Lung cancer risk from residential radon: meta-analysis of eight epidemiologic studies. $\mathcal{F}$ Nat Cancer Inst 1997;89:49-5

3 Warner KE, Mendez D, Courant PN. Toward a more realistic appraisal of the lung cancer risk from radon: the effect of residential mobility. Am F Public Health 1996;86:1222-7.

4 Chaffey CM, Bowie C. Radon and health-an update. $f$ Public Health Med 1994;16:465-70.

5 Lucie NP. Radon exposure and leukaemia [letter]. Lancet 1989;ii:99-100.

6 Henshaw DL, Eatough JP, Richardson RB. Radon as a causative factor in induction of myeloid leukaemia and other cancers. Lancet 1990;335:1008-12.

7 Alexander FE, McKinney PA, Cartwright RA. Radon and leukaemia [letter]. Lancet 1990;335:1336-7.

8 Mole RH. Radon and leukaemia [letter]. Lancet 1990;335: 1336.

9 Bowie SHU. Radon and leukaemia [letter]. Lancet 1990; 335:1336.

10 Prentice AG, Copplestone JA. Radon and leukaemia [letter]. Lancet 1990;335:1337.

11 Baverstock KF. Radon and leukaemia [letter]. Lancet 1990 335:1337-8.

2 Butland BK, Muirhead CR, Draper GJ. Radon and leukaemia [letter]. Lancet 1990;335:1338-9.

13 Collman GW, Loomis DP, Sandler DP. Childhood cancer mortality and radon concentration in drinking watert in North Carolima. Br F Cancer 1991;63:626-9.

14 Lubin JH, Linet MS, Boice JD Jr, et al. Case-control study of childhood acute lympho-blastic leukaemia and residential radon exposure. F Natl Cancer Inst 1998;90:294-300.

15 Richardson S, Monfort C, Green M, et al. Spatial variation of natural radiation and childhood leukaemia incidence in Great Britain. Stat Med 1995;14:2487-501.

16 Thorne R, Foreman NK, Mott MG. Radon in Devon and Cornwall and paediatric malignancies. Eur $\mathcal{F}$ Cancer 1996; 32A:282-5.
17 Kohli S, Sahlén K, Löfman O, et al. Individuals living in areas with high background radon: a GIS method to identify populations at risk. Comput Meth Programs Biomed 1997;53:105-12

18 Kohli S, Sahlén K, Sivertun A, et al. Distance from the primary health center: a GIS method to study geographical access to health care. $\mathcal{F}$ Med Syst 1995;19:425-36.

19 Breslow NE, Day NE. Statistical methods in cancer research. Volume II-The design and analysis of cohort studies. Lyon: International agency for research on cancer, 1987: chapter

20 Breslow NE, Day NE. Statistical methods in cancer research. Volume II-The design and analysis of cohort studies. Lyon: International agency for research on cancer, 1987:93-5.

21 Committee on the Biological Effects of Ionizing Radiation. Board on Radiation Effects Research. Commission on Life Sciences. National Research Council. Health effects of exposure to low levels of ionising radiation: BEIR $V$. Washington, DC. National Academy Press, 1990:48-9.

22 Walter SD. The ecologic method in the study of environmental health. I. Overview of the method. Environ Health Perspect 1991;94:61-5.

23 Cartwright RA, Alexander FE, McKinney PA, et al. Leukaemia and lymphoma:an atlas of distribution within areas of England and Wales 1984-1988. London: Leukaemia Research Fund, 1990

24 Pobel D, Viel JF. Case-control study of leukaemia among young people near La Hague nuclear reprocessing plant: the environmental hypothesis revisited. BMF 1997;314: $101-6$.

25 Gilman EA, Knox EG. Geographical distribution of birth places of children with cancer in the UK. Br F Cancer 1998; 77:842-9.

26 Alexander FE, McKinney PM, Cartwright RA. Migration patterns of children with leukaemia and non-Hodgkin's lymphoma in three areas of northern England. F Public lymphoma in three areas

27 Knox EG, Gilman EA. Hazard proximities of childhood cancers in Great Britain from 1953-80. 7 Epidemiol Community Health 1997;51:151-9.

28 Bithell JF, Stewart AM. Pre-natal irradiation and childhood malignancy: a review of British data from the Oxford Survey. Br 7 Cancer 1975;31:271-87.

29 Wakeford $\mathrm{R}$. The risk of childhood cancer from intrauterine and preconceptional exposure to ionizing radiation. Environ Health Perspect 1995;103:1018-25.

30 Doll R, Wakeford R. Risk of childhood cancer from fetal irradiation. Br f Radiol 1997;70:130-9.

31 Mole RH. Childhood cancer after prenatal exposure to diagnostic x-ray examinations in Britain. Br f Cancer 1990; 62:152-68.

32 Gardner MJ, Snee MP, Hall AJ, et al. Results of case-control study of leukaemia and lymphoma among young people study of leukaemia and lymphoma among young people 300:423-9. [Erratum in BMf 1992; 305:715].

33 McLaughlin JR, King WD, Anderson TW, et al. Paternal radiation exposure and leukaemia in offspring: the Ontario case-control study. BMf 1993;307:959-66. [Errata in BMJ 1993;307:1257 and 1462]

34 Doll R, Evans HJ, Darby SC. Paternal exposure not to blame. Nature 1994;367:678-80.

35 Draper GJ, Little MP, Sorahan T, et al. Cancer in the offspring of radiation workers: a record linkage study. BMF 1997;315:1181-8. 